\title{
On the Harmony of Feminist Ethics and Business Ethics
}

\author{
JANET L. BORGERSON
}

I $\mathrm{f}$ business requires ethical solutions that are viable in the liminal landscape between concepts and corporate office, then business ethics and corporate social responsibility should offer tools that can survive the trek, that flourish in this well-traveled, but often unarticulated environment. Feminist ethics has preceded business ethics and corporate social responsibility into crucial domains that these fields now seek to engage. Indeed, feminist ethics has developed theoretical and conceptual resources for mapping, investigating, and comprehending these complex, often undefined, realms and, moreover, greeting and communicating with the diverse human beings who make their lives there. Nevertheless, feminist ethics has been consistently overlooked, misunderstood, and improperly applied within business ethics and corporate social responsibility. This article provides conceptual clarification, illustrative examples, and furthermore develops a framework for future research.

This article demonstrates that the common and consistent failure in the business ethics context to make basic differentiations between feminist and feminine ethics, as well as conflating feminist ethics with care ethics has resulted in misapprehension, theoretical misunderstanding, and, most importantly, missed opportunities to benefit from feminist ethics' extensive and flexible assets. "Feminist ethics," "feminine ethics," and "care ethics" each designates potentially fertile, yet at times wholly discrete, realms of philosophical insight. Crucial and fundamental discord exists among them.

Janet L. Borgerson is Reader (Associate Professor) in Philosophy and Management in the School of Business and Economics, University of Exeter, UK. 
I argue that feminist ethics has yet to live up to its potential in business ethics and corporate social responsibility in part because many researchers in these fields have failed to recognize four key points:

1. Feminist ethics and feminine ethics are different;

2. All versions of care ethics are not founded upon feminine traits and characteristics;

3. Care ethics and feminist ethics are different; and

4. Feminist ethics is not merely a version of "postmodern ethics."

Whereas confusion remains around these four basic points in the business ethics literature, a scholarly search can reveal numerous publications over the decades that have clearly differentiated, distinguished, and mobilized the discreet potentials of the diverse positions (e.g., Borgerson 2001; 2005b; Derry 2002; McNay 2000; Noddings 1984; Nunner-Winkler 1993; Tong 1997; Tronto 1993; Whitbeck 1983). Whereas aspects of care ethics and feminine ethics arguably have potential contributions to make in business ethics research (White 1998), the focus of this essay will remain on feminist ethics to elucidate potential resources for business ethics. Throughout the course of this article, I address each misunderstanding in turn in hopes of providing a more accurate and useful rendering of feminist ethics.

After presenting the philosophical background of feminist ethics and feminist ethical theory, I illustrate the four misunderstandings, including a textbook case of the misrepresentation and underestimation of feminist ethics within the domain of business ethics. Then, to begin expressing the harmony of feminist and business ethics, I discuss crucial intersections of interest emerging around concepts of relationships, responsibility, and experience. A research example demonstrates how feminist ethical awareness intervenes in business ethics research, countering the tendency to employ "gender differences" in the study of "ethical sensitivity"-defined as "an ability to recognize that a particular situation poses an ethical dilemma," and exemplifies intolerance toward unethical behaviors, and a proneness to do the right thing (Collins 2000: 6). In conclusion, I provide examples of three feminist ethicists "in action" whose investigations into (1) the "grey zones" of harms; (2) identity and representational conventions; and (3) the enlarging potential of "asymmetrical reciprocity" provide insight into feminist ethics' analytic power. First, however, I ask "Why feminist ethics?" and provide an orientation regarding this article's theoretical sympathies. 


\section{WHY FEMINIST ETHICS?}

Feminist ethics calls attention to relationships, responsibility, and experience and their cultural, historical, and psychologic contexts. Strikingly, whereas compelling business ethics scenarios often call for experience in the organization and engagement with the context at hand, traditional ethical considerations that aim at versions of principle-based objectivity and universality often judge such experience and attention "inappropriately subjective" or "unworthy of consideration" in solving problems and coming to terms with conflicts of interest. In other words, a gulf sometimes emerges between business ethics discussions and the way dilemmas are actually resolved.

Moreover, in much ethical discourse, notions of responsibility typically function in reference to fulfilling-usually abstractduties and obligations provoking scarce investigation into the implied relations. The importance of relationships, or sociality, lies at the core of business organization and practices. Nevertheless, responsibility's more comprehensive and insightful modes-as a context for agency based in relationships, developed and borne out intersubjectively or in conjunction with others-have little hope of emerging within traditional discussions of business ethics and corporate social responsibility, yet become apparent readily in feminist ethics.

The field of feminist ethics simultaneously draws upon and develops theoretical foundations that question and pose alternatives to traditional ontological and epistemological assumptions. Fundamental reflection unveils productive possibilities. To put this another way, feminist ethics engages broad concerns of interest, motivating powerful and novel ways of thinking and, furthermore providing diverse approaches to central issues in business ethics and corporate social responsibility (e.g., Calás and Smircich 1997; Derry 2002). In extending the context for feminist ethical interventions in the areas of business ethics and corporate social responsibility, this essay animates key concepts derived from feminist ethics, and reveals that-far from being limited to discussions based in gender differences-feminist ethics provides pathways for recognizing, evaluating, and addressing ethical problems generally. 


\section{ORIENTING THEORETICAL SYMPATHIES}

Echoing Rosemarie Tong's concerns for bioethics, if business ethics does not want to become "just a subfield of law-another rule, regulation and policy generating enterprise," if it wants to encourage and support investigation of and interventions in difficult ethical questions and conflicts, then "it must make some changes" (Tong 1996: 89). This article is informed by analytic philosophy, including analytic philosophers' work in feminist ethics, but also in some respects by philosophical work in existential phenomenology. As this term may appear unfamiliar to some, let us define it. Phenomenology, as the study of the movement of consciousness through time-including the way things appear to us-becomes existential with an emphasis upon understanding diversities of human experience in the world, including notions of lived experiences' contingency and uncertainty. Moreover, the body and particular conditions of embodiment become lenses for comprehending intersubjectivity, engagement, and relations with others. In short, this article explores the harmony of feminist ethics and business ethics, mobilizing an existential-phenomenological perspective, broadly conceived.

A number of prejudices and habits of thinking may lurk in business ethics' philosophical background-militating against opportunities for Tong's called-for "changes"-and influential Oxford philosopher G. J. Warnock provides a relevant example. In his entertaining commentary on what he undoubtedly views as unfortunate Hegelian influences on late 19th-century English philosophy, Warnock (1969) insists that most people are not wracked with existential concerns, such as how to live. He writes, "to practice philosophy in the manner of [G. E.] Moore, it is not necessary to have (as most of us doubtless have not) nor pretend to have (as some at least would be unwilling to do) large-scale metaphysical anxieties. It is necessary only to want to get things clear" (Warnock 1969: 42). Clarity, seemingly, is not what Warnock found in Hegel—an influential theorist in existential phenomenology's background; apparently "large-scale metaphysical anxieties" are not only rare, but also decidedly pretentious distractions in "real" philosophy.

Animating a prominent philosophical brand as Warnock does here calls attention to the delineation of philosophical questions, 
including the kinds of questions philosophy—and as a result, philosophically informed business ethics-has the potential, or inclination, to raise. This is not to say that analytic philosophy will take business ethics and corporate social responsibility down a dead-end road. However, the particular resources displayed thus far arguably have been unsuccessful in wresting business ethics and corporate social responsibility away from those who would indeed turn them into a "rule, regulation, and policy generating exercise." Perhaps if these fields are to flourish and philosophy is to play a part, then turning to alternative perspectives such as feminist ethics and, moreover, remaining open to the potential of an existential phenomenological perspective, offer a productive opportunity as the impact of global business and corporate social responsibility continues to grow.

\section{FEMINIST ETHICS: ACCESSING THE FIELD}

Feminist ethics places the tendency to value connection-and demonstrate alternatives to traditional notions of autonomy-outside conventional visions of a natural or an essential female-gender-based way of being in the world. Feminist ethics turns instead to concrete and particular, yet theoretically elaborated, cultural and historical understandings of diverse marginal or subordinated groups' experience.

Furthermore, tendency to critical inquiry, especially regarding the frequently forgone "givens" of particular situations marks feminist ethics not as a list of essential sex-based ethically relevant traits or a set of predetermined gender-based applicable principles, but rather as an intervention that calls for active engagement in dilemmas. The following sections elaborate on important aspects of feminist ethics, including a brief discussion of the distinction between sex (female) and gender (feminine).

\section{Feminist Interventions and Investigations}

Feminist ethics states a motive for investigating the ethics of an ethos itself. The word ethic, derived from the Greek ethos, refers to the disposition, character, or fundamental value peculiar to a specific person, people, culture, or movement, and usually is conceived of as a set of principles of right conduct or a theory or system of moral values. Feminist ethicists have insisted that "The process 
by which a community arrives at its standards or moral norms is itself open to moral scrutiny" (Brennan 1999: 864), forcing attention upon the context and structure of moral reflection and judgment and attending to signs of oppression. Such an understanding clearly evokes an array of questions: How does an ethos make itself known? How is the ethos experienced in day to day life? Or in law? Why do some people or groups have one ethos rather than another? Claudia Card, articulating the work of feminist ethics, writes, "oppressive sexual politics sets the stage for ethical inquiries into character, interpersonal relationships, emotional response, and choice in persistently stressful, damaging contexts" (Card 1991: 5). In other words, the systematically subordinated positions in which women have found themselves-throughout global history-provoke a range of ethical investigations.

In addition, the concerns of feminist ethics exceed women's oppression and engage the welfare of other groups as well. Feminist ethics often operates against the backdrop of traditional ethical theories' marginalization of females generally. However, feminist ethics articulates, theorizes, and works to understand modes of exclusion, subordination, and oppression-and the damage inflicted by these processes and practices. And, clearly, females have not been the only segment, nor the private domestic sphere the only arena, marginalized or excluded from the traditional vision of moral theory (Tong 1993: 224). Indeed, as Alison Jaggar argues, the concepts of traditional moral theory were often "ill-suited to the contexts under discussion," failing to account for the experience of many within those contexts (Brennan 1999: 861). Moreover, writes Susan Sherwin, "feminist ethics proposes that when we engage in moral deliberation, it is not sufficient just to calculate utilities or to follow a set of moral principles. We must also ask whose happiness is increased, or how the principles in question affect those who are now oppressed in the circumstances at hand" (Sherwin 1996: 52). In short, feminist ethics pays attention to who tends to benefit from a particular way of viewing, evaluating, and philosophizing about the world, and who tends to bear the burden.

\section{Recognizing the Sex/Gender Distinction}

A fundamental theoretical issue must be recognized in this discussion, that is, the distinction between sex and gender. By marking 
the sex/gender distinction, it becomes clear in what ways a "female" perspective differs from a "feminist" perspective. Moreover, a proponent of "care" ethics may distinguish some aspects of care from stereotypically articulated "feminine," self-sacrificing caring behaviors, yet nevertheless not take on board a feminist perspective. "Gender" is "used as an analytic category to draw a line of demarcation between biological sex differences and the way these are used to inform behaviors or competencies, which are then assigned as either 'masculine' or 'feminine'" (Pilcher and Whelehan 2004: 56). To put this another way, behaviors and traits associated with females are often termed "feminine"; in turn, males' characteristics and behaviors are often termed "masculine." Yet it is clear that masculine and feminine traits are not necessarily connected to males or females.

Stereotypically masculine traits can be prominent in females, and stereotypically feminine traits can describe certain gestures in males. Indeed, many traits and behaviors said to be masculine or feminine have no "natural" or essential connection to either sexed body. Rather, it could be said that male and female human beings learn and adopt these gendered traits, behaviors, and roles depending on the social and cultural requirements of their families, communities, and cultures at particular points in history. Moreover, whereas a color such as blue can be "gendered" masculine, this is not a claim that blue is a naturally "male" color.

The distinction between sex and gender allows researchers to separate biological sex difference from traits and characteristics that are often stereotypically gendered. Thus, feminist ethics claims that self-sacrificing caring traits are not naturally occurring female traits, but rather that females in certain places and at certain times for various reasons have had self-sacrificing caring traits forced upon them as appropriate to their sex. As these traits and concomitant roles are enforced and modeled in female lives, the traits and roles are said to be "natural," an essential part of being female. The concerns with naturalizing traits and roles that damage human lives and the connection of this with feminist ethics will be explored in depth below.

\section{Differentiating Feminist Ethics and Care Ethics}

Let us explore more specifically the way in which care ethics and the feminine-trait-based ethical positions that followed (e.g., Noddings 
1984; Ruddick 1989) diverge from feminist ethics. Tong succinctly articulates the distinction that has emerged between feminist ethics and versions of care ethics: "any approach to ethics so naïve as to celebrate the value of caring without caring who cares for whom is not feminist" (Tong 1996: 72). Given the common erroneous sense that feminist ethics is care ethics, and given the goal of this essay, it will be useful to explicitly differentiate the positions here.

Psychologist Carol Gilligan, routinely recognized as a forerunner in feminist ethics, remains a relevant, though troubled starting point (e.g., White 1998: 11). Focused upon moral development-as exhibited in decision making around ethical dilemmas-Gilligan's research challenged attributions of moral superiority usually granted to those research subjects who solved the ethical dilemmas by referring to abstract values derived from universal principles (Gilligan 1982). Her work responded to psychologist Lawrence Kohlberg's influential hierarchical scale of moral maturity, based in dominant Kantian notions of rational morality. Gilligan's early studies - of her subjects' ethical deliberations—revealed "different" approaches, perspectives, or voices, including a voice of "care," that defied abstract, universal positioning. Kohlberg's scale would judge them inferior, yet Gilligan argued that these voices deserved recognition for mature moral reasoning: a care perspective was different, yet equally capable of morally mature judgment.

These alternative ethical considerations - centered around values of care and heard most often in Gilligan's female subjects' voiceshave been misapprehended as expressing an essentially female ethos, or women's natural way of being. In fact, Gilligan never identified the caring voice with the voices of all, and only, women. Whereas sexual dualism - the opposing and hierarchical ordering of male and female-and female gender roles increase the likelihood that a female "voice" expresses care, great variation persists in who voices care and why.

In later research, Gilligan (1995) made a crucial distinction between a feminine ethic and a feminist ethic. Conceptions of femininity-understood theoretically as the subordinated element in the gender dualism masculinity/femininity-carry meanings derived from often associated essentialized female traits, such as passivity, irrationality, and desire to nurture even at the expense of self. A feminine ethic in a patriarchal social order is an ethic of "special obligations and interpersonal relationships." Gilligan writes, 
"Selflessness or self-sacrifice is built into the very definition of care when caring is premised on an opposition between relationships and self-development" (Gilligan 1995: 122). To put this another way, a relationship informed by so-called feminine traits emerges as fundamentally unequal-a one-sided concern with the well-being and development of others that demands prior assumption of female sacrifice made unproblematic by essentialist claims. In other words, combining traditional modes of femininity with notions of responsibility and caring puts into play a particularly debilitating permutation of ethical agency, where agency is understood as action that "transcends its material context" (McNay 2000: 22). In short, the ability to act suffers under a feminine ethos, or a feminized way of being.

Alternatively, by remaining reflective upon potential sites of oppression and subordination, feminist ethical theory informs care ethics' focus on relation differently. A feminist ethic "begins with connection, theorized as primary and seen as fundamental in human life" (Gilligan 1995: 122). In this context, "disconnection" and expectations of autonomy appear as problems. Such a perspective shares certain conceptual points with Emmanuel Levinas' model of responsibility; but as I argue later, adaptations of Levinas' ethical model often underestimate feminist ethics' fundamental contribution. Feminist ethics bears witness to intersubjectivity-or the interrelatedness of subject positions-yet maintains or develops "the capacity to manage actively the often discontinuous, overlapping or conflicting relations of power" (McNay 2000: 16-17).

Whereas some versions of care ethics take up this feminist perspective, others do not. Sherwin (1996) writes, "some feminists have argued that if we are to recommend a place for caring in ethics, we do so only in conjunction with a political evaluation of the role of caring in our moral deliberations, and others have rejected caring outright as the central element of feminist ethics" (p. 51). She continues, "I do not believe it is appropriate to characterize the ethics of care as specifically feminist. It does not capture the dimensions that I regard as distinctively feminist" (p. 51). Many, if not most, researchers in feminist ethics concur with Sherwin, and considerable work has been done to explicate precisely why this is so. Hence, care ethics and feminist ethics are different, though at times certain articulations of care ethics may express feminist concerns. 
In attempting to bring together insights manifested in light of such perspectives, focus and reflection on embodied experience of marginalized existence often produce observations on-and new understandings of-living with, enduring, and attempting to resist forms of exclusion, subordination, and oppression; and furthermore may generate instances of previously unrecognized diversity and variation, frequently evoking, demonstrating, and elaborating alternative ontological and epistemological mappings that provoke rethinking of typical mainstream understandings of meaning, being interaction and theorizing itself. By motivating an investigation of feminist ethics' theoretical foundations, a stronger and expanded contribution from feminist ethics will be forthcoming.

\section{FEMINIST ETHICAL THEORY}

Generally, feminist ethical theories are those that aim "to achieve a theoretical understanding of women's oppression with the purpose of providing a route to ending women's oppression [and] to develop an account of morality which is based on women's moral experience" in the sense that, previously, women's experience has been excluded (Brennan 1999: 860). However, this attempt to gather and comprehend varieties of experience in particular contexts-that formerly remained beyond philosophical ethics' consideration-is not a claim about how women naturally, and hence necessarily, experience the world. Indeed, what we want to be cautious of in the present endeavor is that "in our efforts to explain various realities that are saturated with the weight of the interests that created them, we often present 'neat' versions of reality to suit our agendas" (Gordon 1995: 133).

Tong has condensed the most important feminist ethical contributions into what she calls "challenges to the assumptions of traditional ontology and epistemology" (Tong 1993: 49-77). Ontologically, the dualism of self versus other, or individual versus community-in which the discrete existence of each element is linked to conceptions of autonomy-becomes a question of relationships between self and other and responsibilities of self to the other, and visa versa, in particular contexts. That is, feminist ethical theory attempts to account for intersubjectivity, or interrelations between moral agents even as the boundaries between these become 
blurred. These interactions include situations of inequality and power rather than contracts among assumedly equal partners. In addition, traditional oppositions in epistemology such as abstract versus concrete knowledge, universal versus particular standpoints, impartial judgment versus partiality, and reason versus emotion also fall under scrutiny.

The epistemological shifts in feminist ethical theory require a sensibility that maintains a closer contact with practice and the particular and, hence, remains receptive of concrete experience's details and insights. Investigations undertaken from a feminist ethical perspective are less likely to accept elements and structures of a dilemma as given. To put this another way, feminist ethical theories often spur expansion of the contexts in which problems are to be understood, allowing a broader range of problem recognition, possible solutions, and, moreover, preemptive work (see Dienhart 2000: 263; Weston 1992). So, for example, whereas research in business ethics has explored the phenomenon of "ethical sensitivity" (e.g., Collins 2000: 11) as a gender difference issue that expresses aspects of apparently natural female, or sex-based, virtues, feminist ethics refuses to essentialize, or treat as naturally occurring, socalled women's experience, thus provoking productively alternative inquiries into "ethical sensitivity." As Card argues, feminist ethics calls upon us to interrogate the very occurrence and manifestation of such "sensitivity."

\section{MISUNDERSTANDING FEMININST ETHICS: A TEXTBOOK CASE}

The following discussion-focused on one main textual exampleillustrates the impetus to collapse the field of feminist ethics into a "theory" that reduces to a common ontological trope of essentialized female traits and characteristics assumedly drawn upon in ethical "consideration." Business Ethics (Crane and Matten 2004; 2007), an influential business ethics textbook published by the prestigious Oxford University Press, provides an obvious yet not inconsequential site of analysis for relevant confusions regarding feminist ethics. Interestingly, Fisher and Lovell's textbook (2003) places a brief, uncritical, yet reasonable discussion of care ethics under a broader section on virtue ethics-pairing care with "wisdom" (pp. 74-75). 
Velasquez (2002) provides a superior discussion of care ethics in his well-established textbook. Although he does not elaborate on feminist ethics at all, he nevertheless provides an informed and useful articulation of care ethics, which avoids conflating feminist ethics and care ethics.

Although presenting the familiar ethical perspectives arguably relevant for business ethics-utilitarianism and deontology-Crane and Matten also include short sections on "virtue," "feminist," "discourse," and "postmodern" ethics. Business ethics desperately needs this augmentation. Nevertheless, the text inaccurately reduces feminist ethics to "care ethics," mistakenly grounds care ethics in a "feminine approach," and moreover states that a feminist ethical perspective solves ethical problems by "intuition" and "personal, subjective assessment" (Crane and Matten 2007: 112). Such a set of misunderstandings and conceptual confusions explains much about the remarkable underestimation of feminist ethics in business ethics.

Feminist ethics, a field of philosophical research in itself, appears somewhat misleadingly within both the first and second editions of Business Ethics under the heading of "Contemporary Ethical Theories" (Crane and Matten 2004: 95; 2007: 110)_ defined as those theories that include "consideration of decisionmakers, their context, and their relations with others as opposed to just abstract universal principles" (2004: 95). In short, such a theory would offer consideration for ethics emerging from concrete positions and particular situations rather than prescribe preordained principles or duties in choosing or judging the good or right thing to do. Thus, traditional ethical theories, and more recent versions derived from them (e.g., Rawls 1971), are set against contemporary ethical theories. Indeed, contemporary ethical theories often retain aspirations for seeing the bigger picture yet at the same time, seriously consider details that traditional ethics' approaches have been known to distain and disregard. Nevertheless, various contradictions arise in attempting to generalize "effects" of a certain ethic, or ethos, on all others and in all situations.

Moreover, this understanding obscures the provocative and fundamental tenuousness that feminist ethics locates in notions of essentialism, necessity, and universality. In the wake of feminist ethics' ontological and epistemological shifts, the impact of such essentialist assumptions would emerge as a site for critical analysis. 
In the short "Feminist Ethics" section (Crane \& Matten 2004: 97-8; 2007: 111-113), "male approaches" are directly contrasted with "feminist perspectives." This ill-conceived opposition suggests a lack of understanding around the distinction between sex and gender basic to thinking in feminist theory and feminist ethics. Employing coherent concepts in the explication of feminist ethics as a contemporary ethical theory would require marking masculinity's distinction from the male and femininity's distinction from the female. Indeed, given that essentialist notions of "being" male or female are rejected in feminist ethics, it is a theoretical error to speak of a universally recognizable male or female mode of ethical reflection, response, or action as the text does.

As discussed earlier, the "feminist" term in "feminist ethics" designates a theoretical position distinct from both a "female" or a "feminine" perspective. Indeed, a more accurate introduction to feminist ethics would interrogate why aspects of stereotypical femininity such as being passive, emotional, other-focused, or "sensitive"-often expected of, imposed upon, and developed in female bodies in certain groups, times, and places, including in contemporary Western society-are more likely to coordinate with and express a "care ethic," than are corresponding "masculine" aspects. This likelihood of embodied females taking on, exhibiting, and acting out-often subordinating-feminine traits in a sexist context is recognized as a problem with which feminist ethics has been particularly concerned.

In addition, notions of female "intuition"-presented by the textbook as a source of feminist ethics' ethical response-reduce "feminist ethics" to an informal process of applying feminized female common sense. For example, "Feminism rather proposes a particular attitude toward ethical conflicts that is more within the framework of what women would allegedly do by intuition anyway" (Crane and Matten 2007: 112). Of course, "feminism" does not concern only women. Furthermore, this glaring gaffe marks a fundamental misunderstanding and reiterates dualist notions of men as rational and women as "intuitive." As Jean Grimshaw puts it, "the view that women do not act on principle, that they are intuitive and more influenced by 'personal' considerations, has so often been used in contexts where women have been seen as deficient that it is well to be suspicious of any distinction between women and men which seems to depend on this difference" (Grimshaw 1993: 43). This 
diminutive characterization exacerbates the underestimation of feminist ethics. Moreover, as these misunderstandings have been reproduced in the new edition of the textbook, the impact on students and others who turn to this source will be witnessed for years to come.

\section{NOT ALL CARING RELATIONSHIPS ARE FEMINIST: FACING LEVINASIAN ETHICS}

The debate over which characteristics are crucial for ethical agency, including appropriate approaches to responsibility, has been around for some time; yet the attempt to privilege so-called feminine virtues, for example certain forms of "caring," without careful consideration of their context defies the wisdom of centuries of antisexist work (Wollstonecraft 1975/1790; Young 1990: 73-91). Feminist criticisms of feminine trait-based ethics have raised crucial questions about damaging relationships, desirable boundaries, and ethical agency under oppressive conditions (e.g., Borgerson 2001).

In Western patriarchal culture and in other cultures as well, being has traditionally been divided into two. This binary mode has given rise to well-recognized, hierarchically ordered dualisms of meaning and being: the self/other, white/black, heaven/earth, civilized/primitive, rational/irrational, finite/infinite dichotomies that Val Plumwood finds implicated in the "logic of colonialism" (1993: 51-55). The field of feminist ethics recognizes that processes of ontological "othering" have perpetuated and reinforced historically evident privileging of the male, the white, and the rational (Goldberg 1993).

Traditionally, philosophers have granted ethical superiority to traits and behaviors arising from a stereotypically masculine way of being. Kant, for example, in his Observations on the Feeling of the Beautiful and the Sublime insists upon maintaining the "charming distinction that nature has chosen to make between the two sorts of human beings" (Kant 1960: 77). In this context, males exemplify capacities for depth, abstract speculation, reason, universal rules, and principles. Females are said to be modest, sympathetic, sensitive, and capable of particular judgments, but not principles. In Kant's philosophical universe, this "charming distinction" 
leaves women unilaterally unable to attain full ethical agency. Feminist ethics has attempted to confront the impact of such sexist dualisms.

However, given this traditional underestimation, should not feminist ethics welcome the opportunity to award female contributions and feminine characteristics their long-overdue recognition of moral or ethical worth? After all, the reevaluation of ghettoized caring traits has opened up discussions of the role of care-taking and relationships with others within ethics generally, including a much-heralded challenge to notions of disembodied, contextless, autonomous agents. Moreover, women's experience of relationships seems to suggest the permeable nature of boundaries between individual beings, self, and other, pointing out possibilities for communication between persons, rather than contracts (Held 1993: 28).

Nevertheless, designations of "typical" feminine or masculine habits of deliberation, no matter how apparently virtuous, maintain a troublesome and damaging sexist dualism not extinguished even as the value of traits shift. Socialized female and stereotypical feminine traits have long been valued by philosophers as "charming distinctions" appropriate to women's ways of being, yet this valuing has not changed the overall judgments of female ontological and epistemological potential (see e.g., Card 1996: 49-71; Sherwin 1996: 49-54). Thus, in the field of ethics and western philosophy generally the legacy of hierarchical dualism dominates, even in the work of those who in other contexts seem extraordinarily concerned with power, subordination, and marginality.

For example, Levinas-inspired ethicists elaborating responsibility for and response to the Other-in ways that echo a feminine version of caring-have not listened to the feminist call for full consideration of histories of subordination both in theory and lived experience. In Closeness: An Ethics (Jodalen and Vetlesen 1997), philosophers working in the "ethics of proximity" reassert a kind of essential human responsiveness in the face of the Other, but disconnect the apparently related human traits from sexist and racist dualisms.

Caring - in particular, feminine trait-based caring-often opposes concern for self with concern for other (Card 1996), evident when a self-forgetting caring response is held in contrast to alternative modes of being. The ethics of closeness, or proximity, emerges from 
a phenomenological conceptual lineage, especially from the apparent move beyond phenomenology by Levinas. From this perspective, human beings express their freedom in their response to the Other, not in a cognitive process, of willing or "taking" responsibility, not as a matter of contract or reciprocity, but as a precondition to being human (Jodalen and Vetlesen 1997: 1-19). They write, "Responsibility means to respond, to respond to the call for responsibility issued wordlessly from the Other and received pre-voluntarily by the subject" (1997: 9). This formulation, an example of "having" responsibility, raises an interesting paradox. The manner of response that a Levinas-inspired intimate ethic lauds is precisely the kind of response demanded of subordinate being, evoking a traditional feminine caring or mothering model (see e.g., Gilligan 1982; Noddings 1984).

Yet, Levinasian responsibility is proposed as simply human (cf. Borgerson 2001: 82-84; Nietzsche 1998: 36-37). The lack of reflection upon such essential "responsibility" and, moreover, the failure to acknowledge the shared oppressions of subordinated peoples leave crucial domains of ethics untouched by the "bare givenness of intersubjectivity," or a Levinas-inspired vision of human relation (Jodalen and Vetlesen 1997: 7). To put this another way, the one who must answer the call becomes uncritically feminine, invoking the interrelations of oppressions that share position and characterization in semiotically and existentially relevant dualistic hierarchies.

Indeed, work in feminist theory and philosophy of race suggests that other-centeredness will be recognized most readily in semiotically associated oppressed groups (Gordon, 1997; Stack 1993). In ignoring the critical discourse from, specifically, the field of feminist ethics, proponents of ethical closeness have steered clear of acknowledging the relation between the mode of being they celebrate and the actual circumstances of those who have modelled and still modelwillingly or not-those behaviors, regardless of whether there is anything essentially ethical about them (Bell 1993: 17-48). In other words, the "proximity ethics" interpretation of Levinas-and arguably Levinas himself-fails to incorporate insights from feminist ethics into the notion of responsibility based in uncompromising intersubjectivity, ignoring the ethical implications of being a particular human being, or kind of agent, in contexts of marginalization, subordination, and oppression. 


\section{Feminist Ethics is Not Merely a Version of Postmodern Ethics}

Many of the insights credited to "postmodern ethics," as discussed in Crane and Matten (2004; 2007: 115-118), could be derived from work in feminist ethical theory-as will be discussed later-and indeed often emerged earlier within feminist thought. In equally relevant exclusions, critical race theory (e.g., Gordon 1997) and disability studies (e.g., Shildrick 2005) raise crucial, complex issues of identity, intersubjectivity, and agency, and-this should be obvious - not only as a result of specific engagement and ideological agreement with poststructural theory or thinkers. Insights that have emerged from the experiences, innovations, and theorizations of marginalized groups-such as women, racial minorities, and the disabled-often ascribed solely to what is known as postmodern theory and poststructural theorists. Such careless attribution both reveals and breeds ignorance (and worse) and serves to reintroduce the marginalization such theory often seeks to acknowledge.

Whereas feminist ethical theory does share some fundamental assumptions with poststructural theory-a ground for the so-called postmodern ethics-this emerges not because all feminist theory, and therefore feminist ethics, is derivative. Rather, many feminist philosophers and theorists, as well as their critical race theory and disability studies colleagues, have trained in similar intellectual traditions-philosophical phenomenology, epistemology, and semiotics-as, for example, have Foucault, Deleuze, and Derrida (Borgerson 2005a). Sharing, therefore, academic heritage and disciplinary genealogies, feminist ethical theory has, in some instances, exploited derived tools to develop conceptual and practice-based contributions often along the lines of gender, theoretically understood (Alcoff 1988; Diprose 1994; Walker 1998). Such work includes attention to the intersecting meanings, instantiations, and functionings of hierarchical dualisms in lived human experience, and thus has implications beyond gender difference (Borgerson 2001).

Considerable development in various disciplinary territories has been cultivated with insights derived from theorizing multiple and particular experiences of living in divergent societies, places, times, and bodies. Yet, recognition of such fundamental data tends to vanish in attempts to maintain the status of an abstract and authoritative voice. Given this observation, it is not surprising that a certain kind of discourse intimately connected to, and privileged by, this "tradition" 
continues processes of exclusion and marginalization. Focusing upon feminist ethics as a feminine trait-based ethic of care concerned with "harmonious and healthy social relationships" and relying upon "personal, subjective reasoning" (Crane and Matten 2004: 98) underestimates and undermines the critical power of feminist ethics' analytical examinations and philosophical arguments around unequal power relations, agency and identity formation, and systemic subordination. We turn, now, to three key concepts that emerge from feminist ethics.

\section{INSIGHTS FROM FEMINIST ETHICS}

Recognizing, of course, that conceptual foundations and debates are as diverse in feminist ethics as in other fields of philosophy, for present purposes three theoretical signposts will be indicated as fundamental to feminist ethical terrain. These include attention to responsibility in conjunction with the recognition of the primacy of relation-including aspects of co-creative intersubjective agencyand a focus upon particular experience in context. Whereas alternative aspects of feminist ethics' rich genealogical conceptual heritage could also inspire us here, feminist ethical theories' reframing of responsibility, relationships, and experience adequately exemplifies new possibilities for the impact, complexity, and potential of business ethics.

Robin Derry, in particular, has argued that feminist ethical theory, and related research methods, "could significantly extend the scope of issues addressed and the depth of learning from research in the field of business ethics" (Derry 2002, 81). As a brief example, consider elements of an "ethical decision-making process" offered for business decision making (e.g., Hartman 2001: 6). First, "identify the dilemma." Second, "obtain unbiased facts." Next, identify a variety of choices; identify stakeholders; then "identify the impact of each alternative on each stakeholder and the stakeholders' resulting impacts on you and your firm" (Hartman 2001: 6); and so on.

At each of these steps, rich understandings from feminist ethicsof relationships, responsibility, and experience, as explicated in the following sections-could provide resources for spurring crucial inquiry in these ethical investigations. Readers are encouraged to reflect upon the way in which aspects of relationships, responsibility, 
and experience would expand and in some cases rearticulate responses to each step of such an ethical decision-making process checklist (cf. Weston 1992: 12-36).

\section{Relationships}

Traditionally, relationships might be hypothesized as between autonomous individuals (agents); or between agents who themselves are the products of relations and therefore, represent some modified version of autonomy. Arguments have been made in business ethics stating that autonomy must be the basis for ethical action and reflection-with a focus on recognizing the sight of agency, decision making, and, of course, blame tending to minimize incidences of multiple influence, manipulation, and chance. However, reflection on relationships and intersubjectivity's interference with autonomy models has provoked alternative articulations of autonomy (Lippke 1995). For example,

The idea is not that we should involve others in our deliberations because they will help us come to the right decision. Rather, because the question is always what to do in light of the various relationships we have to others, there is no way of specifying the right decision independent of others' input. And since the relevant relationships are often reciprocal, appropriate deliberation must often be collective. (Darwall 1998: 224)

Stephen Darwall points to the distinction between acknowledging the fundamental role of relationships and accepting a more vulgar understanding of an almost democratically compromised autonomy.

In a theoretical model of co-creation and development, these relationships could be understood as formed between the self, or subject, and some other, in and across a hypothesized gap that separates these agents and protects their status as independent, responsibility-bearing decision makers. The interactions and exchanges form the basis of subject, and self, formation and the development of relationships over time. Feminist ethical notions of self/other relations-as Tong's notion of ontological shifts suggests-are largely intersubjective and interdependent in just this way: that is, self and other are conceived of as developing in relation with each other. 
Indeed, calling attention to intersubjectivity and interdependence raises varying degrees of doubt about the very nature of the distance that supposedly separates self and other, and this provides a critical context for interrogating autonomy. In ethical theory, relationships have often appeared threatening to autonomy and moral integrity because of the role strict boundaries in individual rational decision making and choice have played in making one's decisions one's own (see Card 1996: 21-48). Feminist ethical theory faces this threat to the perceived site of agency, examining and observing revealed contradictions and emergent insights, yet acknowledging that relationships-actual or imagined, lived or theoretically conceptualized-form the foundation for notions of responsibility.

Paying greater attention to the fundamental role of relationships in human existence invokes notions of responsibility to and for others beyond traditional moral contract-based and principle-justified duties and obligations. Furthermore, human agents may be conceived of as "having" or "taking" responsibility. Manifestations of this discussion are wide ranging and complex, and will be developed later in the next section.

\section{Responsibility}

As Darwall notes above, human embeddedness in relationships, our intersubjectivity, cannot be disregarded in discussions and elaborations of responsibility. Card writes:

The challenge is to show how the importance and point of responsibility can survive the realization that the quality of our character and our deeds is not entirely up to us as individuals. (Card 1996: 22)

Responsibility is often understood to describe an ability to respond to a situation-whether this involves another person, a group, or simply a scenario in which one acts to accomplish an action-and may take the form of recognizing or refusing ties, duties, or obligations that we have in relation to this world around us. Such a notion may also be expanded to include possibilities of responsibility to self.

Alternatively, Levinas turns to being-in-relation's inescapable sociality, a scenario in which the challenge is to recognize and accept, as human beings, responsibility for the other in a preexisting relation (Levinas 1985). This is a case of what Card would call 
"having" rather than "taking" responsibility (Card 1996). For Levinas, this response scenario is demanded by ethics, the foundational mode of intersubjectivity, a "face to face" relation of responsibility for the Other that Levinas calls the "curvature of intersubjective space" (Levinas 1969: 290-291, cited in Oliver 2001: 204). In this sense, each must choose to recognize their responsibility, yet there is no choice about entering into the relationship itself as this has emerged in "the bare givenness of intersubjectivity." Ethics, the condition of the always already existing intersubjectivity, sets the stage for appropriate modes of responsibility. Whereas Levinas offers a complex vision of responsibility, its lack of feminist reflections embeds a troubling lack of boundaries, as discussed earlier. For now, Card's notion of "taking" responsibility shall be the focus.

Card (1996) argues that whereas someone or something may have responsibility for a set of situations or actions, taking responsibility requires a center of agency, a choosing to act or follow through in a certain way. This has implications in a feminist ethical context in that females and other subordinated groups may be perceived as having less agency if they have not chosen their responsibilities. In other words, being unable to choose one's responsibilities, having them thrust upon one, may have ontological implications. In short, over time, certain groups may be perceived as unable to "take" responsibility. Diverse scenarios exist: "We may be given responsibility, assigned it, inherit it, and then accept or refuse it" (Card 1996: 29). Card continues, "Agents are more responsible when they take responsibility in a sense that shows more initiative than when they do not" (29). As Larry May has argued, tracing "initiatives" and hence responsibility in groups requires understandings of realms in which shared actions take place and attitudes and values are transformed (May 1992).

Card designates four different senses of taking responsibility each with its own related accomplishments (Card 1996: 28):

1. Administrative or managerial-estimation and organization of possibilities, deciding which should be realized and how

2. Accountability-being answerable or accountable, either through specific agreement or "finding" oneself such, for something and following through 
3. Care-taking - a commitment of support or backing of something or someone, and holding to the commitment

4. Credit-taking the credit or blame for something that did or did not happen, "owning up"

Administrative or managerial responsibility clearly involves decision making, setting out boundaries, and suggesting the form that various organizational processes will take. Being responsible in the sense of being "accountable" reflects the position to which others will turn when decisions have been made, outcomes are under scrutiny, or results are in. Care-taking here invokes a commitment, perhaps a promise, to put resources or support behind a person or project and seeing this through to an end. In other words, one does not withdraw support from a person or project that is expecting such, even if perceived outcomes have changed. Taking responsibility in the sense of credit or blame may evoke not the decision-making process or following or supporting something through to an end; rather credit or blame may fall to one outside the general workings of organizational or institutional processes.

For Card, "having" responsibility cannot generate the same sense of agency as "taking" it, perhaps undermining the very means by which responsible actions are produced. In this way, contexts that encourage "having" rather than "taking" responsibility, may provide support for unethical behaviors and attitudes. Taking responsibility requires an active willingness: and what kind of agent manifests such willingness becomes an issue for investigation. Of course, some people, or agents, may not be willing to "take" responsibility in these ways if as a result they incur more burdens or blame than they would have had otherwise. There is, then, a potential flight from responsibility — or bad faith — that remains troubling. Levinas, for example, engages this concern, attempting to place ethics and relations of responsibility beyond human choice. Feminist ethics, instead, tends to elaborate on being a certain kind of agent, and, thus, having particular kinds of experiences.

\section{Experience}

Knowledge gained through experience in situations not generally regarded as morally relevant nevertheless generates ways of functioning and modes of decision making that have broad ethical import. Feminist ethics has taken a special interest in the understandings 
acquired by particular, often marginalized, groups and individuals. Ethical investigations that include such perspectives require listening to others' voices and emphasizing a broader acknowledgement of human interaction and attention to the lives people lead.

As Iris Marion Young has noted, descriptions of experience express "a subject's doing and undergoing from the point of view of the subject" (Young 1990: 13). Therefore, "talk about experience expresses subjectivity, describes the feelings, motives, and reactions of subjects as they affect and are affected by the context in which they are situated" (Young: 13). Vikki Bell discusses experience in conjunction with the notion of embodiment (Bell 1999: 113-138). In the sense that in the past, notions of embodiment were understood as invoking an essentialist stance, Bell argues that "being 'antiessentialist' need not be a reason not to consider the phenomena and import of embodiment" (Bell: 132). She suggests theorizing "the body in a way that captures the import of the proximity of the body, the debt of identity to the body" (Bell 1999: 132). Echoing this recognition of the impact of particular histories and position on a subject's perspective, Grimshaw writes, "Ethical concerns and priorities arise from different forms of social life" (Grimshaw 1993: 42). Experience emerges through and with diverse and nonsubstitutable modes of embodiment.

Feminist ethical theory may push us to critically reflect on a phenomenon rather than simply assume its merits, and hence interrogate the emergence and effects, for example, of "ethical sensitivity." May has argued that sensitivity to the lives of others and their particular experiences can serve as an opening to acting ethically in relation (May 1992). Whereas sensitivity to others has often been understood as feminine gender's domain, May does not find such an essentialized limitation necessary, rather regarding sensitivity a basic human capacity that can be cultivated.

Recalling Hobbes' statement in The Leviathan, May points out that the opportunity to learn and develop from experience is one of the fundamental equalities that exists in the state of nature (May 1992: 130). Clearly, such an opportunity is altered by prevailing experiential circumstances: and ultimately, some people seem to learn more than others from the lessons of their lives and even succeed in applying these to solve future dilemmas. Moreover, there is no guarantee that the lessons learned point toward "ethical" behavior and actions, sensitive or otherwise, as life is not an ethically reliable teacher. 
Focus on acknowledgment of lived experience and learning invites a distinction between the "natural" and "unnatural" conditions under which people make choices including recognition of how histories of oppression circumscribe the contexts in which relationships and responsibility emerge. Card writes, "It is not enough to confront the inequities of the 'natural lottery' from which we may inherit various physical and psychological assets and liabilities. It is important also to reflect on the unnatural lottery created by networks of unjust institutions and histories that bequeath to us further inequities in our starting positions and that violate principles that would have addressed, if not redressed, inequities of nature" (Card 1996: 20). Being born into a situation may be a "natural fact," but how the nation or race into which one is born has been treated historically and how various effects emerging from these historical variables will place a newborn are not natural facts. Contingent - though not necessarily accidental-historical circumstances, shaped and held in place by systems of power and status, may be ascribed to the just and unjust functioning of "institutions": Such institutions may be as intimately related to an individual as her family relations, her skin color, and her gender. The following section explicates the impact these insights from feminist ethics could have on research in business ethics.

\section{SHARED RESEARCH CONCERNS: REVISITING "ETHICAL SENSITIVITY"}

To explore further feminist ethics' potential to impact research being done in the field of business ethics, I turn to the example of "ethical sensitivity." The Journal of Business Ethics has given witness to the role that ethical sensitivity plays in ethical dilemmas in business contexts (Collins 2000). As suggested in the introduction to this essay, feminist ethical theory opens understanding around the issue of "ethical sensitivity," offering insight into, and tools to address, the concern that "many gender studies lack a theoretical framework that predicts when and why women are more ethically sensitive than men" (Collins 2000: 11). The emphasis upon relationships, responsibility, and lived experience found in feminist ethics provides penetration into the realm of business that traditional moral theories may fail to accomplish. 
Ethical sensitivity has often been examined in terms of gender differences, in particular, an interest in whether women's so-called feminine characteristics, including caring traits, form the foundation for greater ethical sensitivity. As Collins has noted, the results and conclusions have been mixed (see e.g., Shultz and BrenderIlan 2004: 305-6). However, conceptual innovations and analysis motivated by feminist ethics suggest that ethical sensitivity could be studied as a matter of attention to certain details, more obvious, compelling, and relevant to some ethical agents than to others.

Recall that feminist ethical conceptualizations support the conclusion that context matters. To put this another way, feminist ethical theory encourages us to explore why it is that agents with experience of certain kinds-for example, a lived awareness of intersubjectivity and particularity arising in daily life practices and culturally socialized ways of being still regularly expected of and manifested in women in contemporary Western cultures-are more likely to be ethically sensitive. (What such agents ultimately do, of course, is a different question.)

The contributions of feminist ethics push us beyond an essentialist view of gender difference-that bases female predilection for ethical sensitivity in an unfathomable natural, "intuitive," or even cognitive, difference - to conceive, perceive, and construct alternative and supplementary understandings that can be mobilized, theorized, and applied in future scenarios. Thus, the phenomenon of ethical sensitivity emerges as an outcome of specific epistemological and ontological assumptions and cultural preconceptions that play out in lived experience of being female, or conversely male, at a historically specific time and place. In short, ethical sensitivity derives from experience generally and, further, out of experience in relationships of responsibility with others. Such critical reflection gives us a depth of perspective regarding ethical tendencies and traits. The next section investigates three feminist ethicists in action.

\section{FEMINIST ETHICS IN ACTION: THREE EXAMPLES}

As suggested above, feminist ethics in many ways preceded business ethics into areas now recognized as of concern to business ethics and corporate social responsibility, such as complex relations of power between unequal parties. Feminist ethicists drew upon theoretical 
insights derived from bringing to bear notions of responsibility, relationships and experience informed by the challenging, shifting, and reformulating of basic ontological and epistemological assumptions. Examples from the work of three prominent feminist ethicists, Claudia Card, Margaret Urban Walker, and Iris Marion Young are offered to demonstrate the way feminist ethical insights inform analysis, articulation, and intervention in the world-past, present, and future.

The context and depth of these philosophers' theoretical work is far greater than can be expressed in brief here. Readers are encouraged to seek out the writings of these and other feminist ethicists on their own. Moreover, insofar as bioethics engages critical contours of business and organizational practices the works of feminist bioethicists such as Tong, Sherwin, and Wolf are indispensable (e.g., Sherwin 1996; Tong 1997; Wolf 1996).

\section{Claudia Card: Harm and "Grey Zones"}

Card, a student of John Rawls, demonstrates in The Atrocity Paradigm (2002) philosophical strengths gleaned from charting and developing the concepts, dimensions, and ultimately the field of feminist ethics. She defines "evil" most basically as "foreseeable intolerable harms produced by culpable wrongdoing" (Card 2002: $3)$. She writes, "One reason that many evils go unrecognized is that the source of harm is an institution, not just the intentions or choices of individuals (many of whom may not share the goals of the institution, even when their conduct is governed by its norms). Another is that the harm is the product of many acts, some of which might have been individually harmless in other contexts. Victims are more likely than perpetrators to appreciate the harm. But when the source is an institution, even victims can be hard-pressed to know whom to hold accountable" (Card 2002: 24-25). Particularly in situations in which privilege meets disadvantage, wealth meets poverty, or power meets constraint-constantly emerging for example in globalized labor, or international health research practices (Borgerson 2005b)—decision-making processes to avoid real harms in the face of apparent benefits become ever more opaque.

"Feminists," writes Card, "have long struggled with the question of how ethically responsible agency is possible under oppression, given that oppressive practices are coercive" (Card 2002: 234). In 
her discussion of "the grey zone," Card elaborates on "the complex and difficult predicaments of some who are simultaneously victims and perpetrators." Such a situation might be seen arising in a rural community adjusting, for example, to the presence of new outsourced factory work in which some people come to hold the means of survival for others, perhaps suddenly, perhaps with nearly impossible demands from those further up the supply chain. What Card argues is that, "evils may be prevented from perpetuating themselves in a potentially unending chain as long as victims who face grim alternatives continue to distinguish between bad and worse and refuse, insofar as possible, to abdicate responsibility for one another" (Card 2002: 26). Some of her analysis specifically addresses social institutions; nevertheless discussions of "institutions" might as well suggest the organization or corporation. Card argues that institutions that create "grey zones," sometimes intentionally, are particularly culpable.

\section{Margaret Urban Walker: Moral Understandings and Representational Practices}

Walker contends that the assumption that people are a kind or type is propagated and created by representational practices, which "are among those that construct socially salient identities for people" (Walker 1998: 178). She argues that if practices of representation "affect some people's morally significant perceptions of and interactions with other people, and if they can contribute to those perceptions or interactions going seriously wrong, these activities have bearing on fundamental ethical questions" (p. 179). That is, a person influenced by such images may treat members of the represented group as less than human or undeserving of moral recognition.

Drawing upon and developing such insights allow marketing communications scholars to articulate the way in which representations are part of lived experience. Representations from advertising images, film, and the Internet inform and co-create notions of reality. Mobilizing an "ethics of representation" can sensitize international marketing campaigns to their interactions with, and impact upon cultural difference, global race relations, and the constitution of the consuming subjects (Ahmed 2000; Borgerson and Schroeder 2002, 2005; Chouliaraki 2006; Schroeder and Borgerson 2005). 
Philosophers concerned with ethical norms and behavior have traditionally proceeded as though all problematic situations of moral recognition could be countered in three ways: through constructive definitions of personhood, through formal requirements of universality or universalizability, and through substantial demands for impartial or equal consideration (Walker 1998). From Walker's feminist ethical perspective, these three formulations lack sufficient conceptual strength to handle representations that characteristically manipulate and damage the identity of subordinate groups. Moreover, these prescriptions fail to provide sufficiently complex considerations to deal with problems of representation and, worse, damaging representations often fail to even qualify as ethical or moral problems.

Not surprisingly, then, we find in Robert Solomon's chapter on business ethics a discussion of "consumer intelligence and responsibility" including issues of advertising. The use of "sex"-apparently referring to displayed sexuality - to lend appeal to products and "the offensive portrayals of women and minorities" become a "lack of taste": But, asks Solomon, is it "an ethical issue?" What Solomon utterly misses here is advertising's role beyond appeal, information, and persuasion, its perpetual representation of an entire vision of life and the world around us, often provoking responses and consequences equivalent to and as "serious" as "outright lying in advertising" (Solomon 1993: 362; cf. Borgerson and Schroeder 2002; Schroeder and Borgerson 2005; Vaver 2008; Schroeder 2008).

\section{Iris Marion Young: Asymmetrical Reciprocity}

Young addresses the issue of attempting to understand "the point of view of others before drawing conclusions about what is right or just," for example in encouraging a more privileged group to fairly consider the importance of some benefit to a less privileged group. Believing in the potential for dialog between people that happens "across difference without reversing perspectives and identifying with each other" Young finds the common sense thought experiment of "putting yourself in the place of the other" not only misleading and politically suspect, but reinforcing "subjective understanding of issues," disregarding the "nonsubstitutable relation of moral subjects" and disrupting opportunities for what she calls enlarged thought (Young 1997: 39). 
This response to work on theories of communicative ethics invokes "asymmetrical reciprocity" based on a subject's unique temporality and position, and moreover recognition of asymmetry of power, opportunities, and understandings. Young writes, "with regard to the Hegelian ontology of self and other, each social position is structured by the configuration of relationships among positions. Persons may flow and shift among structured social positions, and the positions themselves may flow and shift, but the positions cannot be plucked from their contextualized relations and substituted for one another" (Young 1997: 52). Work in business ethics and corporate social responsibility that requires "efforts to express experience and values from different perspectives"-as discussions between corporations and countries do-may take note of the dangers of collapsing diverse perspectives and experiences into "shared" expectations. Furthermore, recognition of inequalities, and the opportunities they offer, may help build understandings, for example, of the way trust works, or does not, in corporate and organizational environments (e.g., Gustafsson 2005).

This article has sought to clarify what business ethics can learn from feminist ethics-understood in a robust way that makes an educated exploration of resources beyond care ethics and uncritical notions of femininity. The introduction of three feminist ethicists in action attempts to bring to light notions that business ethics and corporate social responsibility might find useful. Nevertheless, this is only a brief sketch, and the true benefits of engaging with feminist ethics, as with most areas of philosophy, may only emerge with further reading and reflection.

\section{CONCLUSION}

As has been suggested here, feminist ethics in many ways preceded business ethics into areas of concern that business ethics and corporate social responsibility now seek to engage in. This includes the work of feminist ethics in developing theoretical and conceptual resources for charting courses through these complex, often unarticulated, realms.

Feminist ethics does more than displace traditional ethical voices, only to assert a "different" voice with alternative concerns. As illustrated in the preceding discussions, simply asserting the 
primacy of relationships, recognizing the existence of permeable boundaries between the self and the other, and questioning the site of agency may fail to attend to the existential-phenomenological realities of intersubjectivity and responsibility-including issues of power-that shed light on business ethics and organizational environments. This requires noting both in theorizing, and in day-to-day life experience, that lack of boundaries between self and other-as evoked in the case of Levinas' ethics, but also often in some care ethics and feminine ethics-may have dangerous effects and, moreover, forms the typical situation of oppressed groups.

Furthermore, an insistence on residing closer to understandings of lived experience may have a particular attraction challengingyet making sense to-those who work in business contexts, and who can be expected to invoke on-site experience-based insights that traditionally trained business ethicists may lack. The underestimation of feminist ethics in business ethics could be viewed as in unfortunate continuity with modes of privileged, traditional philosophical discourse that have ignored, excluded, and subordinated marginalized alternative views of identity, society, and the world for centuries. However, business ethics, a field with its own shadowed subordinations and feminized margins, may well defy the underestimation of feminist ethics, recognizing powerful philosophical opportunities and conceptual innovations in the potentially harmonious landscape of feminist ethics and business ethics.

\section{ACKNOWLEDGMENTS}

I want to thank David Bevan, Laura Hartmann, Campbell Jones, Jonathan Schroeder, and the anonymous reviewers for support on this project.

\section{REFERENCES}

Ahmed, S. 2000. Strange Encounters: Embodied Others in Post-Coloniality. London: Routledge.

Alcoff, L. 1988. "Cultural feminism versus post-structuralism: The identity crisis in feminist theory." Signs 13(3): 405-436.

Bell, L. 1993. Rethinking Ethics in the Midst of Violence: A Feminist Approach to Freedom. Lanham, MD: Rowman and Littlefield.

Bell, V. 1999. Feminist Imagination. London: Sage. 
Borgerson, J. L. 2001. "Feminist ethical ontology: Contesting the "bare givenness of intersubjectivity'." Feminist Theory 2(2): 173-189.

Borgerson, J. L. 2005a. "Judith Butler: On organizing subjectivities." Sociological Review 53(October): 63-79.

Borgerson, J. L. 2005b. "Addressing the global basic structure in the ethics of international biomedical research involving human subjects." Journal of Philosophical Research special supplement: 235-249.

Borgerson, J. L., and Schroeder, J. E. 2002. "Ethical issues in global marketing: Avoiding bad faith in visual representation.” European Journal of Marketing 36(5/6): 570-594.

Borgerson, J. L., and Schroeder, J. E. 2005. Identity in marketing communications: An ethics of visual representation. In A. J. Kimmel, ed., Marketing Communication: New Approaches, Technologies, and Styles, pp. 256-277. Oxford: Oxford University Press.

Brennan, S. 1999. "Recent work in feminist ethics.” Ethics 109(July): 858-893.

Calás, M. B., and Smircich, L. (eds.) 1997. Predicando la moral en calzoncillos. Feminist Inquiries into business ethics. In A. Larson, and R. E. Freeman, eds., Business Ethics and Women's Studies. Oxford, England: Oxford University Press.

Card, C. 1991. Feminist Ethics. Lawrence: University Press of Kansas.

Card, C. 1996. The Unnatural Lottery: Character and Moral Luck. Philadelphia: Temple University Press.

Card, C. 2002. The Atrocity Paradigm: A Theory of Evil. Oxford: Oxford University Press.

Chouliaraki, L. 2006. "The aestheticization of suffering on television." Visual Communication 5(3): 261-285.

Collins, D. 2000. "The quest to improve the human condition: The first 1,500 articles published in Journal of Business Ethics." Journal of Business Ethics 26: 1-73.

Crane, A., and Matten, D. 2004. Business Ethics: A European Perspective. Oxford: Oxford University Press.

Crane, A., and Matten, D. 2007. Business Ethics: Managing Corporate Citizenship and Sustainability in the Age of Globalization, 2nd ed. Oxford: Oxford University Press.

Darwall, S. 1998. Philosophical Ethics. Boulder, CO: Westview.

Derry, R. 2002. Feminist theory and business ethics. In R. Fredrick, ed., A Companion to Business Ethics, pp. 81-87. Oxford: Blackwell.

Dienhart, J. 2000. "Just caring, caring justice." Business and Society Review 105(2): 247-267.

Diprose, R. 1994. The Bodies of Women: Ethics, Embodiment and Sexual Difference. London: Routledge.

Fisher, C., and Lovell, A. 2003. Business Ethics and Values. Harlow: Prentice-Hall.

Gilligan, C. 1982. In a Different Voice: Psychological Theory and Women's Development. Cambridge, MA: Harvard University Press.

Gilligan, C. 1995. "Hearing the difference: Theorizing connection." Hypatia 10(2): 120-127. 
Goldberg, D. 1993. Racist Culture: Philosophy and the Politics of Meaning. Oxford: Blackwell.

Gordon, L. 1995. "Rethinking ethics in the midst of violence: A feminist approach to freedom." Sartre Studies International 1(1\&2): 133-150.

Gordon, L. 1997. Her Majesty's Other Children: Sketches of Racism from a Neocolonial Age. Lanham, MD: Rowman and Littlefield.

Grimshaw, J. 1993. "The idea of a female ethic." In P. Singer, ed., A Companion to Ethics, pp. 491-499. Oxford: Blackwell.

Gustafsson, C. 2005. "Trust as an example of asymmetrical reciprocity: An ethics perspective on corporate brand management." Business Ethics -A European Review 14(2): 143-150.

Hartman, L. 2001. "Technology and ethics: Privacy in the workplace." Business and Society Review 106(1): 1-27.

Held, V. 1993. Feminist Morality: Transforming Culture, Society, and Politics. Chicago: University of Chicago Press.

Jodalen, H., and Vetlesen, A. (eds.) 1997. Closeness: An Ethics. Oslo: Scandinavian University Press.

Kant, I. 1960. Observations on the Feeling of the Beautiful and the Sublime, trans. J. T. Goldthwait. Berkeley: University of California Press.

Levinas, E. 1969. Totality and Infinity, trans. A. Lingis. Pittsburgh: Duquesne University Press.

Levinas, E. 1985. Ethics and Infinity, trans. R. Cohen. Pittsburgh: Duquesne University Press.

Lippke, R. 1995. Radical Business Ethics. Lanham, MD: Rowman and Littlefield.

May, L. 1992. Sharing Responsibility. Chicago: University of Chicago Press.

McNay, L. 2000. Gender and Agency: Reconfiguring the Subject in Feminist and Social Theory. Cambridge: Polity.

Nietzsche, F. 1998. On the Genealogy of Morality, trans. M. Clark, and A. Swensen. Indianapolis: Hackett.

Noddings, N. 1984. Caring: A Feminine Approach to Ethics and Moral Education. Berkeley: University of California Press.

Nunner-Winkler, G. 1993. "Two moralities: A critical discussion of an ethics of care and responsibility versus an ethic of rights and justice." In M. J. Larrabee, ed., An Ethic of Care. New York: Routledge.

Oliver, K. 2001. Witnessing: Beyond Recognition. Minneapolis: University of Minnesota Press.

Pilcher, J., and Whelehan, I. (eds.) 2004. 50 Key Concepts in Gender Studies. London: Sage.

Plumwood, V. 1993. Feminism and the Mastery of Nature. London: Routledge. Rawls, J. 1971. A Theory of Justice. Cambridge, MA: Harvard University Press. Ruddick, S. 1989. Maternal Thinking: Toward a Politics of Peace. Boston: Beacon Press.

Schroeder, J. E. 2008. "Brand culture: Trade marks, marketing and consumption." In L. Bently, J. Davis, and J. C. Ginsberg, eds., Trade Marks and Brands: An Interdisciplinary Critique. Cambridge: Cambridge University Press, in press. 
Schroeder, J. E., and Borgerson, J. L. 2005. “An ethics of representation for international marketing." International Marketing Review 22: 578-600.

Sherwin, S. 1996. "Feminism and bioethics." In S. M. Wolf, ed., Feminism and Bioethics: Beyond Reproduction, pp. 47-66. Oxford: Oxford University Press.

Shildrick, M. 2007. "Dangerous Discourses: Anxiety, Desire and Disability." Studies in Gender and Sexuality 8(3): 221-244.

Shultz, T., and Brender-Ilan, Y. 2004. "Beyond justice: Introducing personal moral philosophies to ethical evaluations of human resource practices." Business Ethics: A European Review 13(4): 302-316.

Solomon, R. 1993. "Business ethics." In P. Singer, ed., A Companion to Ethics, pp. 354-365. Oxford: Blackwell.

Stack, C. B. 1993. "The culture of gender. Women and men of color." In M. J. Larrabee, ed., An Ethic of Care: Feminist and Interdisciplinary Perspectives. New York: Routledge.

Tong, R. 1993. Feminine and Feminist Ethics. Belmont, CA: Wadsworth.

Tong, R. 1996. "Feminist Approaches to Bioethics.” In S. Wolf, ed., Feminism and Bioethics: Beyond Reproduction, pp. 67-94. Oxford: Oxford University Press.

Tong, R. 1997. Feminist Approaches to Bioethics: Theoretical Reflections and Practical Applications. Boulder, CO: Westview.

Tronto, J. 1993. Moral Boundaries: A Political Argument for an Ethic of Care. New York: Routledge.

Vaver, D. 2008. "Images in brand culture: Responding legally to Professor Schroeder's paper.” In L. Bently, J. Davis, and J. C. Ginsberg, eds., Trade Marks and Brands: An Interdisciplinary Critique. Cambridge: Cambridge University Press.

Velasquez, M. G. 2002. Business Ethics: Concepts and Cases, 5th ed. Upper Saddle River, NJ: Prentice-Hall.

Walker, M. 1998. Moral Understandings: A Feminist Study in Ethics. New York: Routledge.

Warnock, J. G. 1969. Contemporary Moral Philosophy. New York: St. Martin's Press.

Weston, A. 1992. Toward Better Problems. Philadelphia: Temple University Press.

Whitbeck, C. 1983. "A different reality: Feminist ontology." In C. C. Gould, ed., Beyond Domination. Totowa, NJ: Rowman \& Allenheld.

White, T. 1998. "Sexual harassment: Trust and the ethics of care." Business and Society Review 100/101: 9-20.

Wolf, S. (ed.) 1996. Feminism and Bioethics: Beyond Reproduction. Oxford: Oxford University Press.

Wollstonecraft, M. 1975. A Vindication of the Rights of Woman [1790]. London: Penguin.

Young, I. M. 1990. Throwing Like a Girl and Other Essays in Feminist Philosophy and Social Theory. Bloomington: Indiana University Press.

Young, I. M. 1997. Intersecting Voices: Dilemmas of Gender, Political Philosophy, and Policy. Princeton, NJ: Princeton University Press. 